\title{
SPECTRUM OF BENIGN BREAST DISEASES IN A TERTIARY CARE HOSPITAL OF PUNJAB
}

\author{
Pankaj Srivastava ${ }^{1}$, Prafull Kumar Arya ${ }^{2}$, H. S. Khetarpal ${ }^{3}$, Kavita Shrivastava ${ }^{4}$, Pawan Kumar Singh ${ }^{5}$ \\ ${ }_{13}^{\text {rd }}$ Year Resident, Department of General Surgery, SPS Apollo Hospitals, Ludhiana, Punjab. \\ ${ }^{2}$ Senior Consultant and HOD, Department of General Surgery, SPS Apollo Hospitals, Ludhiana, Punjab. \\ ${ }^{3}$ Senior Consultant, Department of General Surgery, SPS Apollo Hospitals, Ludhiana, Punjab. \\ ${ }^{4}$ Senior Consultant, Department of Pathology, SPS Apollo Hospitals, Ludhiana, Punjab. \\ ${ }^{5}$ Senior Resident, Department of General Surgery, SPS Apollo Hospitals, Ludhiana, Punjab.
}

\section{ABSTRACT}

\section{BACKGROUND}

Benign breast diseases (BBD) constitute a heterogeneous group of disorders including developmental abnormality, epithelial and stromal proliferation, inflammatory lesions and neoplasm. As compared to breast cancers, benign breast lesions are 10 times more common. Benign breast lesions deserve attention because of their high prevalence, their impact on women's life and due to cancerous potential of some histological types.

\section{MATERIALS AND METHODS}

120 cases were diagnosed as BBD after triple assessments like clinical examination, ultrasonography or mammography, FNAC or excisional biopsy. Patients with obvious malignancy were excluded from the study.

\section{RESULTS}

Out of 120 benign lesions, the commonest presentation was breast lump (60\%) commonly involving left upper outer quadrant. Fibroadenoma accounted for $39.2 \%$, fibroadenosis $31 \%$, mastalgia $13.3 \%$, breast abscess about $7.5 \%$ and gynaecomastia $7.5 \%$. The other benign lesions observed were phyllodes, cysts, lipoma, galactocele, mastitis, duct ectasia and accessory breast. In case of fibroadenoma, accuracy of clinical diagnosis vs radiology and pathology was found to be $91 \%$ and $94 \%$ respectively, and $100 \%$ for galactocele and breast abscess.

\section{CONCLUSION}

BBDs are common in females and fibroadenoma is the commonest in all. Triple assessment provided a quick diagnosis and it alleviated unnecessary anxiety for the patients about breast cancer. The clinical diagnosis of the breast lump as confirmed by radiology and pathology was accurate in $91 \%$ and $94 \%$ of cases respectively.

\section{KEYWORDS}

Benign Breast Disease, Fibroadenoma, Triple Assessment, Fibrocystic Diseases, Punjab.

HOW TO CITE THIS ARTICLE: Srivastava P, Arya PK, Khetarpal HS, et al. Spectrum of benign breast diseases in a tertiary care hospital of Punjab. J. Evolution Med. Dent. Sci. 2017;6(79):5602-5606, DOI: 10.14260/jemds/2017/1216

\section{BACKGROUND}

Breast is a dynamic organ which continuously undergoes normal structural and physiological changes like pubertal, cyclical, pregnancy, lactational and menopausal. When these normal changes exceed their limit, they are known as benign breast disease. Benign breast diseases are traditionally considered less relevant diseases as compared to malignancy of breast. ${ }^{1}$

Benign breast diseases constitute heterogeneous group of disorder including developmental abnormalities, epithelial and stromal proliferations, inflammatory lesions and neoplasms. ${ }^{2}$ These include all non-malignant conditions like fibroadenoma, fibrocystic disease, mastalgia, mammary duct ectasia, sclerosing adenosis, lactational adenoma, benign phyllodes tumour, intraductal papilloma, fibrous disease, blunt duct adenosis, calcification, breast abscess, lactational mastitis, puerperal mastitis, granulomatous lobular mastitis,

'Financial or Other Competing Interest': None.

Submission 28-08-2017, Peer Review 22-09-2017,

Acceptance 27-09-2017, Published 30-09-2017.

Corresponding Author:

Dr. Pankaj Srivastava,

Room No. 12, SPS Apollo Hospitals,

Sherpur Chowk, Ludhiana-411003, Punjab.

E-mail: drpankajsrivastava84@gmail.com

DOI: $10.14260 /$ jemds $/ 2017 / 1216$

\section{(c) $($ ()) $\odot$}

fat necrosis, tuberculous mastitis, galactocele, gynaecomastia and lipoma. ${ }^{3}$

These patients generally present with symptoms of breast pain, lump in breast, nodularity, nipple discharge, nipple retraction, ulceration, eczema of nipple, swelling in the axilla, enlargement of breast, etc. Most common clinical presentation is a palpable breast lump followed by breast pain and nipple discharge. 4

Benign breast disorders are usually hormone induced and therefore usually seen in the reproductive period of life with dramatic fall of incidence after menopause.$^{5}$ As compared to breast cancers, benign breast lesions are 10 times more common. ${ }^{1}$ Of all the diagnosed breast diseases, benign lesions account for $90 \%{ }^{6}$ Fibroadenoma is found to be the most common benign breast disease followed by fibrocystic disease followed by breast abscess and mastalgia. ${ }^{3}$

Breast mass is a common complaint along with pain. Such symptomatic masses have been traditionally assessed by clinical, cytological and radiologic modalities like mammography. ${ }^{7}$ Thus, up to $95 \%$ of such lesions could be diagnosed by the triple assessment. Although, the role of FNAC and Clinical examination has been unanimous, ${ }^{8}$ the role of USG instead of mammography has been emphasised recently, ${ }^{9}$ especially in the young female population.

There is evidence that woman who correctly practice breast self-examination monthly are more likely to detect a 
lump in early stage of development and early diagnosis has been reported to influence early treatment to yield a better survival rate. ${ }^{10}$

\section{Aims}

To study the clinical profile of benign breast diseases in relation to age, sex and clinical presentation; to correlate clinical, radiological and pathological findings in patients presenting with benign breast diseases.

\section{MATERIALS AND METHODS}

This is a descriptive study, Observational study which was conducted in the outpatients department of General Surgery in Satguru Partap Singh, Tertiary Care Hospital, Ludhiana, Punjab, from June 2015 to November 2016. A total of 120 patients were treated for falling under BBDs.

\section{Inclusion Criteria}

Which includes all patients with symptom of breast disease including breast pain, palpable breast lump, nodularity, nipple discharge, nipple retraction, ulceration, enlargement of breast and swelling in the axilla were included and all asymptomatic patients coming voluntarily for preventive health checkup.

\section{Exclusion Criteria}

Included all patients with an obvious malignant disease or those who had been treated for malignancy earlier.

Detailed history included age, sex and duration of complaints like lump in breast, pain, fever, nipple discharge or retraction. Detailed menstrual history included age at menarche, regularity of cycles and marital history was also noted. Relevant findings of general, systemic and local examination were recorded. After making an appropriate clinical diagnosis one or more of the special investigations like ultrasound, mammography, FNAC, excisional biopsy or a core-needle biopsy were carried out for the confirmation of the diagnosis. Cytological and histopathological examination was done. Surgically resected specimen included needle biopsy, excisional biopsy and lumpectomy and mastectomy specimen. Specimens not representing the lesion and malignant breast lesions were excluded from the study. Specimens were received in $10 \%$ formalin. Gross features of each specimen were noted and sections were processed by autoprocessor. Paraffin embedded sections were stained by Haematoxylin and Eosin stain. Special stain and immunohistochemistry were performed wherever required. Diagnosis was confirmed by FNAC and/or Histopathology and correlated with clinical and radiological findings wherever available.

\section{Statistical Analysis}

Data were described in terms of range; mean \pm standard deviation $( \pm S D)$, median, frequencies (number of cases) and relative frequencies (percentages) as appropriate.

\section{Settings and Design}

This is a descriptive study, observational study of patients with breast disease presenting to surgery department during
June 2015 to November 2016 at Satguru Pratap Singh tertiary care hospital, Ludhiana, Punjab.

\section{RESULTS}

A total of 120 patients who attended the surgery outpatients department for breast diseases were studied in the Department of General Surgery.

\section{Age Distribution}

The age distribution in our study is shown in Table 1, which reveals maximum numbers of patients were in reproductive age group of 21 - 40 years. The overall range is from 13 years to 69 years and mean age was 38.69. In females, the minimum age of patient was 15 years, whereas the maximum age was 69 and mean age was 38.03 years.

\begin{tabular}{|c|c|c|}
\hline Age (Years) Range & No. of Patients & Percentage \\
\hline $11-20$ & 6 & 5.0 \\
\hline $21-30$ & 28 & $23.3 \%$ \\
\hline $31-40$ & 43 & 35.8 \\
\hline $41-50$ & 24 & $20 \%$ \\
\hline $51-60$ & 11 & 9.2 \\
\hline$>60$ & 8 & 6.7 \\
\hline Total Table 1. Age Distribution \\
\hline \multicolumn{2}{|c|}{} \\
\hline \multicolumn{2}{|c|}{} \\
\hline
\end{tabular}

\section{Sex Distribution}

The sex distribution in our study is shown in Table 2, which reveals maximum number of patients were females with female: male ratio of $11: 1$. Total number of female patients were 110 and male patients were 10 .

\begin{tabular}{|c|c|c|}
\hline Sex & No. of Patients & Percentage \\
\hline Female & 110 & 91.7 \\
\hline Male & 10 & 8.3 \\
\hline Total & $\mathbf{1 2 0}$ & $\mathbf{1 0 0 . 0}$ \\
\hline \multicolumn{3}{|c|}{ Table 2. Sex Distribution } \\
\hline
\end{tabular}

\section{Pattern of BBDs}

The pattern of BBD in our study is shown in Table 3, which reveals that in our study most common BBD was seen in $39.16 \%(47 / 120)$ patients with fibroadenoma followed by FCD seen in about $30.8 \%(37 / 120)$. Out of 47 patients of fibroadenoma, $10 \%(12 / 120)$ patients were diagnosed with both fibroadenoma and fibrocystic disease. Mastalgia was seen in $13.3 \%(16 / 120)$. Out of 16 patients, 10 were having cyclical mastalgia (8.3\%) and $6(5 \%)$ were having noncyclical mastalgia. Breast abscess was present in $7.5 \%$ (9/120) cases. Out of 10 males in our study, 9 (7.5\%) were diagnosed of gynaecomastia and 1 case of mastitis. Other benign diseases noted were breast cyst in $3.3 \%(4 / 120)$, lipoma in $2.5 \%$ $(3 / 120)$, phyllodes tumour in $1.6 \%(2 / 120)$ and mastitis were noted in $1.6 \%(2 / 120)$ cases. Only one case $(0.8 \%)$ of each galactocele, duct ectasia and accessory breast was noted.

\begin{tabular}{|c|c|c|}
\hline Diagnosis & No. of Patients & Percentage \\
\hline Fibroadenoma & 47 & $39.16 \%$ \\
\hline Fibrocystic disease & 37 & $30.83 \%$ \\
\hline
\end{tabular}




\begin{tabular}{|c|c|c|}
\hline Cyclical Mastalgia & 10 & $8.3 \%$ \\
\hline Non-cyclical mastalgia & 6 & $5 \%$ \\
\hline Breast Abscess & 9 & $7.50 \%$ \\
\hline Gynaecomastia & 9 & $7.50 \%$ \\
\hline Breast cyst & 4 & $3.33 \%$ \\
\hline Lipoma & 3 & $2.50 \%$ \\
\hline Mastitis & 2 & $1.67 \%$ \\
\hline Phyllodes tumour & 2 & $1.67 \%$ \\
\hline Accessory breast tissue & 1 & $0.83 \%$ \\
\hline Duct ectasia & 1 & $0.83 \%$ \\
\hline Galactocele & 1 & $0.83 \%$ \\
\hline Total & $\mathbf{1 2 0}$ & $\mathbf{1 0 0 . 0 0 \%}$ \\
\hline \multicolumn{2}{|c|}{ Table 3. Pattern of various BBD } \\
\hline
\end{tabular}

\section{Distribution of Various BBDs according to Age Group}

Distribution of various BBDs according to age group is shown in Table 4 , which reveals that about $36.2 \%$ patients with fibroadenoma belonged to $4^{\text {th }}$ decade of life followed by $27.7 \%$ from 3rd decade of life. FCD was found to be most common in $4^{\text {th }}$ and $5^{\text {th }}$ decade of life. About $37.8 \%$ of patients with fibrocystic disease were from $4^{\text {th }}$ decade and $32.4 \%$ from 5th decade. About $60 \%$ of cases of cyclical mastalgia were from $4^{\text {th }}$ decade of life followed by $30 \%$ from $3^{\text {rd }}$ decade of life. About $33.3 \%$ cases of noncyclical mastalgia were commonly seen in $4^{\text {th }}$ decade. Breast abscess was commonly seen in patients $(44.44 \%)$ of $4^{\text {th }}$ decade followed by $(33.33 \%)$ patients of 5 th decade. Out of 10 cases of breast disease encountered in males, 9 cases $(7.5 \%)$ were of gynaecomastia. About $33.33 \%$ were found in $6^{\text {th }}$ decade, $22.22 \%$ in $>60$ years and remaining were equally distributed in $2^{\text {nd }}, 3^{\text {rd }}, 4^{\text {th }}$ and $5^{\text {th }}$ decades.

Phyllodes tumours were seen in 2 patients from $3^{\text {rd }}$ and $4^{\text {th }}$ decade of life. Similarly, mastitis were seen in 2 patients from $3^{\text {rd }}$ and $4^{\text {th }}$ decade of life; 3 cases of lipoma were found in which 2 were in $4^{\text {th }}$ decade and 1 in $6^{\text {th }}$ decade. Breast cysts were present in $3.33 \%(4 / 120), 2$ patients were $>60 \mathrm{yrs}$. and remaining 2 patients were from $4^{\text {th }}$ and $5^{\text {th }}$ decade of life. Galactocele, duct ectasia and accessory breast which accounted for $0.8 \%(1 / 120)$ of all BBDs were seen in $3^{\text {rd }}, 6^{\text {th }}$ and $4^{\text {th }}$ decade of life respectively.

\begin{tabular}{|c|c|c|c|c|c|c|c|c|c|c|c|c|c|}
\hline \multirow{3}{*}{ Final Diagnosis } & \multicolumn{12}{|c|}{ Age (Years) Range } & \multirow{3}{*}{ Total } \\
\hline & \multicolumn{2}{|c|}{$11-20$} & \multicolumn{2}{|c|}{$21-30$} & \multicolumn{2}{|c|}{$31-40$} & \multicolumn{2}{|c|}{ 41-50 } & \multicolumn{2}{|c|}{$51-60$} & \multicolumn{2}{|c|}{$>60$} & \\
\hline & No. & \% Age & No. & \% Age & No. & $\%$ Age & No. & \% Age & No. & \% Age & No. & \% Age & \\
\hline Fibroadenoma & 5 & $10.6 \%$ & 13 & $27.7 \%$ & 17 & $36.2 \%$ & 6 & $12.8 \%$ & 4 & $8.5 \%$ & 2 & $4.3 \%$ & 47 \\
\hline Fibrocystic Disease & 0 & $0.0 \%$ & 8 & $21.6 \%$ & 14 & $37.8 \%$ & 12 & $32.4 \%$ & 2 & $5.4 \%$ & 1 & $2.7 \%$ & 37 \\
\hline Cyclical Mastalgia & 0 & $0.0 \%$ & 3 & $30.0 \%$ & 6 & $60.0 \%$ & 1 & $10.0 \%$ & 0 & $0.0 \%$ & 0 & $0.0 \%$ & 10 \\
\hline Non-Cyclical Mastalgia & 0 & $0.0 \%$ & 0 & $0.0 \%$ & 2 & $33.3 \%$ & 1 & $16.7 \%$ & 1 & $16.7 \%$ & 2 & $33.3 \%$ & 6 \\
\hline Breast Abscess & 0 & $0.0 \%$ & 2 & $22.2 \%$ & 4 & $44.4 \%$ & 3 & $33.3 \%$ & 0 & $0.0 \%$ & 0 & $0.0 \%$ & 9 \\
\hline Gynaecomastia & 1 & $11.1 \%$ & 1 & $11.1 \%$ & 1 & $11.1 \%$ & 1 & $11.1 \%$ & 3 & $33.3 \%$ & 2 & $22.2 \%$ & 9 \\
\hline Breast Cyst & 0 & $0.0 \%$ & 0 & $0.0 \%$ & 0 & $0.0 \%$ & 1 & $25.0 \%$ & 1 & $25.0 \%$ & 2 & $50.0 \%$ & 4 \\
\hline Lipoma & 0 & $0.0 \%$ & 0 & $0.0 \%$ & 1 & $33.3 \%$ & 0 & $0.0 \%$ & 2 & $66.7 \%$ & 0 & $0.0 \%$ & 3 \\
\hline Mastitis & 0 & $0.0 \%$ & 1 & $50.0 \%$ & 1 & $50.0 \%$ & 0 & $0.0 \%$ & 0 & $0.0 \%$ & 0 & $0.0 \%$ & 2 \\
\hline Phyllodes Tumour & 0 & $0.0 \%$ & 1 & $50.0 \%$ & 1 & $50.0 \%$ & 0 & $0.0 \%$ & 0 & $0.0 \%$ & 0 & $0.0 \%$ & 2 \\
\hline Accessory Breast Tissue & 0 & $0.0 \%$ & 0 & $0.0 \%$ & 1 & $100.0 \%$ & 0 & $0.0 \%$ & 0 & $0.0 \%$ & 0 & $0.0 \%$ & 1 \\
\hline Duct Ectasia & 0 & $0.0 \%$ & 0 & $0.0 \%$ & 1 & $100.0 \%$ & 0 & $0.0 \%$ & 0 & $0.0 \%$ & 0 & $0.0 \%$ & 1 \\
\hline Galactocele & 0 & $0.0 \%$ & 1 & $100.0 \%$ & 0 & $0.0 \%$ & 0 & $0.0 \%$ & 0 & $0.0 \%$ & 0 & $0.0 \%$ & 1 \\
\hline Total & 6 & $4.5 \%$ & 30 & $22.7 \%$ & 49 & $37.1 \%$ & 25 & $18.9 \%$ & 13 & $9.8 \%$ & 9 & $6.8 \%$ & 132 \\
\hline
\end{tabular}

\section{Distribution of Mode of Presentation}

Distribution of mode of presentation of patients in present study is shown in Table 5. The patients were broadly divided into groups depending on their symptoms or presentations such as a breast lump, breast pain, nodularity, enlargement and nipple discharge. Breast lump was the most frequent presentation in $60 \%(72 / 120)$ of patients followed by pain in $49.16 \%$ (59/120) and nodularity in 32.5\% (39/120) patients. Discrete lump was present in $28.33 \%$ (34/120), pain alone in $11.67 \%(14 / 120)$ and nodularity in $10 \%(12 / 120)$. Presentation of lump in relation to pain was found in 23 cases (19.17\%), lumpiness/nodularity in 11 cases (9.17\%) and painful lump with nodularity in 4 cases. Out of 9 patients of gynaecomastia, 5 presented with enlargement of breast associated with pain, while 4 patients presented with solitary enlargement.

\begin{tabular}{|c|c|c|}
\hline Symptoms & $\begin{array}{c}\text { No. of } \\
\text { Patients }\end{array}$ & Percentage \\
\hline Lump & 34 & $28.33 \%$ \\
\hline Pain & 14 & $11.67 \%$ \\
\hline Nodularity & 12 & $10.00 \%$ \\
\hline
\end{tabular}

\begin{tabular}{|c|c|c|}
\hline Lump and Pain & 23 & $19.17 \%$ \\
\hline Lump and Nodularity & 11 & $9.17 \%$ \\
\hline Nodularity and Pain & 12 & $10.00 \%$ \\
\hline Lump, Pain and Nodularity & 4 & $3.33 \%$ \\
\hline Enlargement & 4 & $4.17 \%$ \\
\hline Pain and Enlargement & 5 & $3.33 \%$ \\
\hline Pain and Discharge & 1 & $0.83 \%$ \\
\hline \multicolumn{2}{|c|}{ Table 5. Mode of Presentation } \\
\hline
\end{tabular}

Unilateral breast involvement was present in 99 cases $(82.50 \%)$ and bilateral involvement in 21 cases (17.5\%). LT breast involvement was more common in 56 cases $(46.67 \%)$ and RT breast was involved in $43(35.83 \%)$ cases shown in Table 6. Quadrant wise distribution of lump in BBD is shown in Table 7, which reveals that in present study lesion was most commonly present in upper outer quadrant 33 cases $(27.5 \%)$ and in lower outer quadrant there were 18 cases (15\%). Upper inner quadrant involvement was observed in 5 cases $(4.17 \%)$ and lower inner quadrant in 6 cases $(5 \%)$. Subareolar involvement was seen in 11 cases $(9.17 \%)$ and in 3 cases $(2.5 \%)$ it was diffuse involving all the quadrants. 


\begin{tabular}{|c|c|c|}
\hline Breast Side Involvement & $\begin{array}{c}\text { No. of } \\
\text { Patients }\end{array}$ & Percentage \\
\hline Right Breast only & 43 & $35.83 \%$ \\
\hline Left Breast only & 56 & $46.67 \%$ \\
\hline Bilateral Breasts & 21 & $17.50 \%$ \\
\hline
\end{tabular}

Table 6. Breast Side Involvement

\begin{tabular}{|c|c|c|}
\hline $\begin{array}{l}\text { Breast Quadrant } \\
\text { Involvement }\end{array}$ & $\begin{array}{c}\text { No. of } \\
\text { Patients }\end{array}$ & Percentage \\
\hline Upper outer quadrant & 33 & $27.50 \%$ \\
\hline Lower outer quadrant & 18 & $15.00 \%$ \\
\hline Upper Inner Quadrant & 5 & $4.17 \%$ \\
\hline Lower inner Quadrant & 6 & $5.00 \%$ \\
\hline Subareolar & 11 & $9.17 \%$ \\
\hline Diffuse & 3 & $2.50 \%$ \\
\hline \multicolumn{3}{|c|}{ Table 7. Breast Quadrant Involvement } \\
\hline
\end{tabular}

\section{Clinical and Radiological Correlation}

Radiological examination (USG and Mammography) was done in 118 cases of benign breast disease in our study. Out of 44 clinically diagnosed fibroadenoma, only 40 came to be correct on radiology. Four remaining cases were later found as one cyst, one FCD and two phyllodes tumour. The accuracy of clinical diagnosis was calculated and came out to be $91 \%$.

Similarly, in case of 28 clinically diagnosed FCD 22 were correctly diagnosed on radiology and remaining 6 cases later found as five fibroadenoma and one lipoma. The accuracy of clinical diagnosis came out to be $78.5 \%$.

In case of breast abscess and gynaecomastia, clinical diagnosis was $100 \%$ accurate.

\section{Clinical and Pathological Correlation}

The diagnoses of the lumps were confirmed either cytologically or histologically or in both ways. Pathological examination (FNAC and/or HPE) was done in total 46 cases. In 19 cases only FNAC was done and HPE was performed in 13 cases. Combined FNAC and HPE was done in 14 cases. Surgical excision was done in 23 cases of fibroadenoma and all of them were sent for HPE; 35 cases were clinically suspected as fibroadenoma, out of which 33 had fibroadenoma on pathological examination. The accuracy of the clinical diagnosis of fibroadenoma was $94.28 \%$ (33 out of 35 cases), as 2 cases after pathological examination came out to be phyllodes tumour.

\section{DISCUSSION}

Fibroadenoma was the most common benign breast disease in our study. Our finding was in agreement with most of the available literature on benign breast diseases like Ihekwaba et $\mathrm{al}^{11}$ and Greenberg et al. ${ }^{12}$ However, study conducted by Aisha Memon et $\mathrm{al}^{7}$ and Nadia Adnan Ghani et al ${ }^{13}$ were contrary to our study, in which fibroadenoma was found to be the second most common BBD in female patient. In our study, the fibrocystic disease was the second most common condition. This concurs with findings by Priya Bagale et $\mathrm{al}^{4}$ and Akshara Gupta et al,14 who found that fibroadenoma was the most frequently diagnosed BBD followed by FCD, while results observed by Aisha Memon et al, ${ }^{7}$ Nadia Adnan Ghani et al $^{13}$ and Chaudhary et $\mathrm{al}^{15}$ were contrary to our study in which they found FCD to be the commonest BBD. In present study, Mastalgia were the third most common BBD which was in accordance with Akshara Gupta et al ${ }^{14}$ and Abhishek Sharma et al. ${ }^{16}$ They also observed the same result however Shukla et al ${ }^{17}$ and later Khanna et al ${ }^{18}$ drew attention to the significant incidence of mastalgia. The latter estimated it to account for $70 \%$ of all BBDs. Krishnaswamy et al $^{19}$ also found mastalgia to be a significant problem accounting for $56.9 \%$ of all BBDs. These studies were performed exclusively in urban population, which may account for higher incidence of mastalgia due to high awareness in general population. Fourth most common BBD in present study was Breast abscess, which concur with findings of Priya Bagale et al. ${ }^{4}$ It appears that the figures for breast abscess in this study are underestimated, because most patients with breast abscesses are treated in the primary and secondary centres and are not often referred to tertiary care hospitals such as ours. Similar to our observation, in study done by Olu-Eddo A et $\mathrm{al}^{20}$ gynaecomastia was the most commonly encountered male breast disease.

In our study, the most prominent symptoms was painless lump which was in accordance with study performed by Selvakumaran $\mathrm{S}$ et $\mathrm{al}^{21}$ and Sagar et al. ${ }^{22}$ On the contrary, Krishnaswami et $\mathrm{al}^{19}$ and Shukla et $\mathrm{al}^{17}$ noted mastalgia as the most significant problem. In the current study, left upper outer quadrant was most commonly involved. According to literature as upper and outer quadrant contains bulk of mammary tissue, lumps (benign and malignant) are commonest in that position. Haque et $\mathrm{al}^{23}$ and SP Iyer et al ${ }^{24}$ in their study found similar results. In our study, the accuracy of clinical diagnosis with respect to radiological diagnosis in cases of fibroadenoma, FCD, breast abscess and gynaecomastia was $91 \%, 78.5 \%, 100 \%$ and $100 \%$ respectively.

Similarly, when accuracy of clinical diagnosis with respect to pathological diagnosis was calculated in cases of fibroadenoma it came out to be $94.2 \%$.

\section{CONCLUSION}

BBDs are common in females and fibroadenoma is the commonest in all. Triple assessment provided a quick diagnosis and it alleviated unnecessary anxiety for the patients about breast cancer. The clinical diagnosis of the breast lump as confirmed by radiology and pathology was accurate in $91 \%$ and $94 \%$ of cases respectively.

\section{ACKNOWLEDGEMENT}

I wish to express my sincere gratitude to our Department of Pathology and Department of Radiology for their support and encouragement in carrying out this project work.

\section{REFERENCES}

[1] Bhargava GS, Grover A, Ded KS, et al. Evaluation of benign breast disorders in females of rural Punjab. CIB Tech J Surg 2015;4(1):19-23.

[2] Sharma A, Chanchlani R. A study of spectrum of benign breast diseases in a tertiary care institute of central India. J Evidence Based Med \& Healthcare 2015;2(5):551-5.

[3] Bagale P, Dravid NV, Bagale S, et al. Clinicopathological study of benign breast diseases. IJHSR 2013;3(2):4754.

[4] Sangma MBM, Panda K, Dasiah S. A clinicopathological study on benign breast diseases. J Clin Diagn Res 2013;7(3):503-6. 
[5] Kumar HC, Khadri SI, Kemparaj T, et al. Benign breast diseases: our institutional experience. JEMDS 2014;3(62):13637-44.

[6] Memon A, Parveen S, Sangrarasi AK, et al. Changing pattern of benign breast lumps in young females. World J Med Sci 2007;2(1):21-4.

[7] Morris KT, Pommier RF, Morris A, et al. Usefulness of the triple test score for palpable breast masses. Arch Surg 2001;136(9):1008-13.

[8] Johnsen C. Breast disease. A clinical study with special reference to diagnostic procedures. Acta Chir Scand Suppl 1975;454:1-108.

[9] Bassett LW, Ysrael M, Gold RH, et al. Usefulness of mammography and sonography in women less than 35 years of age. Radiology 1991;180(3):831-5.

[10] Ertem G, Kocer A. Breast examination among nurses and midwives in Odemis health district in Turkey. Indian J Cancer 2009;46(3):208-13.

[11] Ihekwaba FN. Benign breast disease in Nigerian women: a study of 657 patients. J R Coll Surg Edinb 1994;39(5):280-3.

[12] Greenberg R, Skornick Y, Kaplan O. Management of breast fibroadenomas. J Gen Intern Med 1998;13(9):640-5.

[13] Nadia AG. Benign breast disorders-a histopathological study in Tikrit city. Diyala J Med 2012;3(1):27-35.

[14] Gupta A, Gupta AK, Goyal R, et al. A study of clinical profile of benign breast diseases presenting at a tertiary care centre in central India. Scholar J Appl Med Sci 2015;3(2C):695-700.
[15] Chaudhary IA, Qureshi SK, Rasul S, et al. Pattern of benign breast diseases. J Surg Pak 2003;8:5-7.

[16] Sharma A, Chanchlani R. A study of spectrum of benign breast disease in a tertiary care institute of central India. J Evi Based Med Healthcare 2015;2(5):551-5.

[17] Shukla HS, Kumar S. Benign breast disorders in northwestern populations. Part 2. Benign breast disorders in India. World J Surg 1989;13(6):746-9.

[18] Khanna AK, Tapodar J, Misra MK. Spectrum of benign breast disorders in a university hospital. J Indian Med Assoc 1997;95(1):5-8.

[19] Krishnaswamy U. Profile of benign breast diseases in urban India. Indian J Surg 2003;65(2):178-81.

[20] Olu-Eddo AN, Ugiagbe EE. Benign breast lesions in an African population: a 25-year histopathological review of 1864 cases. Niger Med J 2011;52(4):211-6.

[21] Selvakumaran S, Sangma MB. Study of various benign breast diseases. International Surg J 2017;4(1):33943.

[22] Sagar R, Gaddikeri P, Ramakrishna MK. Analytical study of pattern and presentation of benign breast diseases in patients between age group 15 to 35 years. Int J Biomed Res 2015;6(6):412-5.

[23] Haque A, Tyagi SA, Khan MH, et al. Breast lesion. A clinic pathological study of 200 cases of breast lumps. Ind J Surg 1980;42:419-25.

[24] Piyer S, Gore MA. Epidemiology of benign breast disease in females of child bearing age group. Bombay Hospital J 2000;42(1):141-6. 